\title{
Practising Knowing: emergence(y) teleologies
}

Marie Manidis and Hermine Scheeres

Key words: practising, knowing, knowledge, medicine, practices, organisational learning

\section{Abstract}

This article presents a meta disciplinary and institutional framework of practices nurses and doctors use to manage the indeterminacy of knowing in emergency departments (EDs) in Australia. We draw on Schatzkian perspectives of how practices prevail and reflect particular site ontologies (Schatzki 2005).

We posit that nurses and doctors draw on a repertoire of practices, to finesse their knowing at patients' bedsides: they practise knowing. Drawing on existing practice knowledges (old learnings) they tailor them in the ED (new workplace learnings). This suggests that learning (practices) in the ED is teleological and emergent. This alerts us to new ways of thinking about attachments to practice knowledges (Reckwitz 2002), or 'the teleological-affective structuring' of practices (Schatzki 2006), and its implications for organisational learning.

\section{Foreword}

In Hager's recent critical overview of organisational learning theories (2011) we catch a glimpse of the summative legacy of the breadth and depth of his understanding of the field and theoretical terrain of adult and workplace learning. In this article, he outlines the historical trajectory of developmental theorisations in this field. In addressing these shifts, Hager's article discusses how successive theorists remain attached to three key questions in organisational learning: Issue 1) whether individual learning is the best unit of analysis when examining learning in a workplace setting; Issue 2) how learning is seen as a product or 'thing' and finally; Issue 3) how learning might be understood independent of the context in which it takes place. Hager suggests that questions raised in early theoretical perspectives on organisational learning continue to the present time. This alerts us to the way that theory and knowledge emerge over time in robust academic debate.

As he traces the historical developments from the psychologically-based theories, socio-cultural approaches and then post modernist theorisations, Hager's critical overview does not necessarily resolve the issues of individual versus collective learning, learning as product and learning and its relationship to context. But he does warn that researchers and policy makers must think more deeply about 'individualistic and product assumptions' (2011, p. 25), as the field, and practice has been shown to be more complex than this. 
This complexity of practice is evident in the idea we explore in this article, that learning is emergent and teleological. In doing this, we draw on Hager's subtextual referencing of emergence and attachment (2011) by examining more recent theorisations on these aspects of working/knowing as proposed by Schatzki $(2005 ; 2006)$ and Gherardi $(2006 ; 2009)$.

\section{Introduction}

This article presents a meta disciplinary and institutional framework of practices that nurses and doctors use to manage the indeterminacy of knowing in emergency departments (EDs) in Australia. Practices are conceptualised as prefigured and prevailing ways of doing, saying and being, underpinnined by knowledges, teleologies, rules and protocols (Schatzki, 2001; 2002; 2006; 2009). We draw initially on Schatzkian perspectives of how practices prevail and reflect particular site ontologies (Schatzki, 2005), taking a practice-based approach to understanding organisational work and learning.

We posit that practices enacted in standard medical interviews have prevailed as an enduring activity (Roter, 2000) into the institutional setting of emergency departments (EDs) (Fischer \& Ereaut, 2012). Here they continue to be enacted individually, and by implication collectively, to manage the uncertainty, contingency, and indeterminacy of working/knowing in the ED. As they work, we posit that nurses and doctors draw on a repertoire of practices, to finesse their knowing at patients' bedsides in the ED setting: they practise knowing. Working in this high-stress, noisy and disciplinarily divided context, they draw on existing practice knowledges (old learnings) and tailor them to the ED context in particular configurations (new workplace learnings). This suggests that learning (practices) in the ED is both teleological and emergent. We propose that this alerts us to new ways of thinking about attachments to practice knowledges (Reckwitz, 2002), or what Schatzki calls 'the teleological-affective structuring' of practices (2006, p. 1864), and its implications for organisational learning.

We begin this article with an introduction to the research study followed by a brief outline of the pedagogical structuring of medicine and nursing and the ED as a site of knowing. Then we present a meta disciplinary and institutional repertoire of practices that nurses and doctors draw on to practise knowing. Following this, we explore the way teleological attachments to practice knowledges impinge on learning (practices). The article concludes that although knowing is generally portrayed as emergent, knowing is also connected to the taxonomic (and historical) hierarchy of doctors', nurses' and patients' knowledges, and is therefore, also teleological. 


\section{The research site and research methods}

In this article we draw on data collected in five Australian EDs over four years, 2006 - 2010', using linguistic ethnographic (Rampton, 2007) and ethnographic methods suitable for investigating practice (Yanow, 2000; Gherardi, 2006; Schatzki, 2012). Eighty-two clinician patient consultations were audio recorded, transcribed and analysed alongside non-participant ethnographic observations of ED practice conducted over approximately 1,000 hours. We examined the interconnectedness and interdependency of material arrangements, artefacts, language, people, knowledge, time and space (Schatzki, 2005; Gherardi, 2006; 2008; 2009; Nicolini, 2011) as nurses and doctors went about their work. These empirical data sets were supplemented by reflections on practice, through 150 semi-structured interviews held with a wide range of ED practitioners, managerial and administrative staff. Through these interviews, we sought to ascertain views on the ED's 'knowing' practices.

EDs are an integral part of the wider, modern health system in Australia and are complex working and institutional environments. Each ED integrates a number of activities, practices and organisational structures within its charter of service. These extend from core services such as acute medical assessment and treatment services incorporating multidisciplinary healthcare practices to tertiary training ii and referral sites with services linked to community health facilities. EDs are set up to operate within a specifically constructed facility at selected hospitals, based on demographic factors of population density.

\section{EDs as sites of knowing}

Many EDs are attached to tertiary training hospitals, and as such, the Health Departments in Australia (and medical schools) see EDs as learning sites for junior doctors in particular. EDs are places where practising develops 'knowing in action'. What this means is that junior doctors are 'thrown in at the deep end' (although they are closely supervised by more senior clinicians) to put to work what they have learned in medical schools. This in situ component of their training recognises that knowledge is not just an object captured by means of mental schemes; rather it is a practical and collective activity. In situ development recognises that knowing is acquired not only through thought and formal learning, but also through the body and sensory and aesthetic knowledge (Strati, 2003; 2007), and through having to deal with real problems in real time. Thus, junior doctors bring knowledge with them to the ED and they apply this knowledge, while at the same time they are learning new knowledges: together this constitutes knowing in practice. 
From a health policy (and medical colleges) perspective, junior doctors in EDs are institutionally positioned as having high-level knowledge that is valued. Yet when they arrive in the ED on a rotational basis, they lack the in situ experience of senior health care practitioners such as staff nurses who monitor patients closely and who may have been working in the ED for many years. As learners, junior doctors join an established institutional health care team who are individually and collectively experienced. However, it is junior doctors as the medical experts who take responsibility for patients, and they are key decision makers as they 'work up' their patients. They enact, at a personal and intermediate level, the medico-legal responsibility for care, ultimately held by the senior doctor on duty on the day.

It is junior doctors who face greater challenges than most as they develop practices to manage both the certainty and uncertainty of their expertise and their expert roles. As new ED practitioners, they are constantly working on knowing - knowing what and how to do, say and be - in practice. Knowing and not knowing in the ED emerge in the relationships between knowledge and practising and learning, particularly how these are compounded by disciplinary paradigms and institutionalised practices. For example, the nature and pace of ED work (Eisenberg, Murphy et al., 2005), divided disciplinary tasks and the material arrangements of the ED increase the fragility of knowing in this setting. Yet, the ED is a site, like all organisations, in which performances of the unfolding of actions continue to occur 'as the organization happens' (Schatzki, 2006).

Knowledge and knowing are not fixed entities (Orlikowski, 2002; Gherardi, 2006; Yamauchi, 2006; Gherardi, 2009), and particularly in the ED, these are contingent and unstable, increasing the potential for errors and accidents when caring for patients. This reality challenges fixed forms of knowledge, and fixed understandings of safety on which healthcare practice paradigms, and the ED procedures, are largely based. Our data illustrate how knowledge and knowing unfold in practice told as 'stor[ies] of mess and multiplicities' (Hor, 2011) rather than as stable, settled ways of working. Thus, paradoxically, ED work is characterised by both knowing and 'not knowing' (Yamauchi, 2006). For junior doctors in particular, and for the ED, the performance of their knowledge(s), through doings and sayings, continues to unfold as ED care happens, especially in the face of uncertainty and not knowing: they are practising knowing.

The term practising knowing is used to explicate three principal ideas. Firstly it conveys the developmental understanding we explore, of how nurses and doctors finesse their knowing, through their doings and sayings with patients: they practise how to do (and say and be) as they are becoming ED practitioners. Secondly, the term embraces a feigned (although not necessarily unfounded) expertise - where in the roles of nurses and doctors as 'expert[s they are] "supposed to 
know" ' (Lacan, 1977, p 230 - 243 in Bradley, 2009, p. 74-75) - they must present themselves as knowers.

Finally, paradoxically, the term also conveys the equivalence of practising and knowing, i.e. knowledge is equivalent to what doctors and nurses do and say (Gherardi, 2009), practising is knowing. In this latter understanding of the term, nurses and doctors have a repertoire of doings and sayings participating proximally with patients as they talk and gaze; drawing on protocols (which assist them to act); predicting and finessing their knowing as they simultaneously check, read, scan (and thereby confirm) details; assume (and thereby also check and are reminded of patient and collegiate) details; as they reconstitute their knowing.

Doctors and nurses reconstitute what they know about patients as they engage with them. They are constantly checking and revising what they know. This practice is embodied in the way that our own GP might scan our patient records (or explicitly read, depending on how well they know us) as we enter a consultation room. Alternatively, this activity is embodied in the timeless image of a nurse or a doctor looking at a patient chart while standing next to a bed as he or she considers the patient's status and care. In rapid and subtle ways doctors refresh care statuses; they pick up cues from patients' colouring, expressions, breathing; they re-question; they ask assumptive questions and make predictive statements. These are practices recognisable to patients, colleagues and carers. In the ED, nurses and doctors have less time to engage in these 'reconstituting knowing' activities, and they have little foreknowledge of their patients as an ED attends to everyone who comes through its doors. We posit therefore, that as they approach patients, nurses and doctors have adapted standard medical interview practices to this context (in other than immediate lifethreatening cases). Collectively and individually they manage the fragility of knowledge and knowing in the ED space. Doctors and nurses speculate, pre-empt, use protocols, and participate - they don't always know but they practise knowing through their sayings and doings. We frame these within a meta disciplinary and institutional framework of practices.

\section{Managing not knowing and knowing: a meta-disciplinary and institutional practice framework}

We heuristically categorise the practices nurses and doctors undertake to reconstitute their knowing into a four-fold framework as follows: proximal practices; protocol-driven practices; predictive or pre-emptive practices and finally, prefigured participatory practices. We propose that nurses and doctors have learned to enact a repertoire of doings and sayings, (individually and collectively) to manage knowing/not knowing. These practices draw on extant healthcare practices, now 'bundled' 
(Schatzki, 2005) and enacted in particular ways in the ED: although we describe them separately, they are interconnected with each other (see Figure 1 below).

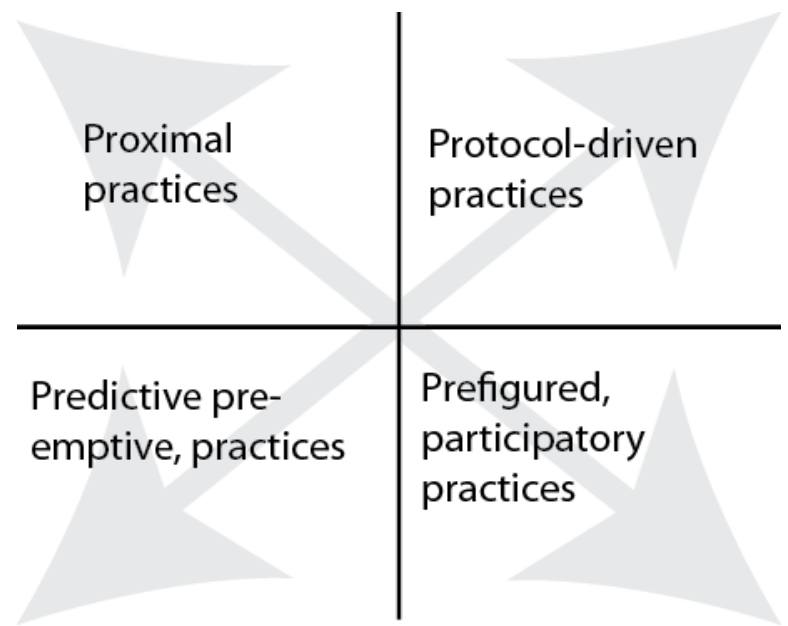

Figure 1, Meta disciplinary and institutional practice framework

We present a scenario to illustrate what we mean by practising knowing. Our patient is 95 -year old Jane Edna who presents one morning at 10.00am with symptoms of lower epigastric pain having experienced chest pain at 06.00am. We examine Nurse 5's interactions with Jane Edna, whom he first sees at $13.52 \mathrm{pm}$. In this initial visit, Nurse 5 spends some time with her and offers the following uncertain advice at that time: and you know that you're being booked in to have a, um, an X-ray, a CT or, it's similar to an $X$-ray. Nurse 5 conducts further observations at $14.07 \mathrm{pm}$ and says to Jane Edna:

N5 Yeah, we can't give you anything at the moment because you've got some pain in your abdomen, we can't give you anything to eat or drink.

$P \quad$ No, I haven't any pain in my abdomen.

N5 In this sort of - in this general area?

$P \quad$ Not at the moment. No.

N5 You've had, you had it today though?

$P \quad$ I have, yes.

N5 Yeah, they just don't want to give you anything um to eat or drink just in case if there is, there is something like a blockage there.

Nurse 5 gets Jane Edna's problematic anatomical area wrong; she corrects him. He proceeds to then take a stab: In this sort of - in this general area? N5 then seeks to confirm some knowledge of why Jane Edna has come in and what she has experienced: You've had, you had it today though? Once Jane Edna confirms this, he proceeds carefully with a reason for why she can't have any food just now. The use of terms such as: something like... sort of general area is his way of getting around the specifics of her care/condition. It is also the way that Nurse 5 reconstitutes his knowing. Orlikowski describes how 'in-the-moment reconstruction of thought and action, knowing may be altered' 
(Orlikowski, 2002, p. 253). For Nurse 5, this is a moment of reflection and experimentation and in this moment Nurse 5's knowing is altered as he experiences and (re)interprets the world.

We now examine Nurse 5's doings and sayings through the four-fold meta framework of practices.

\section{Proximal practices}

The first category of the practice framework we identify is that of proximal practices. Our definition of proximal is intended to convey the almost universal requirement (and practice) of geographic copresence as doctors and nurses interact with patients and the material environment around them and during which they enact actions and interactions, as we see Nurse 5 doingiii. We use the word proximal to go beyond the meaning implied in its physical sense where a doctor or nurse may simply be next to, close to or beside a patient. It serves to describe specifically how knowing is done proximally, through touch, and gaze for example, and in a practice-based context, particularly in medicine and nursing, ways in which knowing is more than a cognitive doing - it is also relational, it is embodied (Strati, 2007). Mol describes how '[l]ong before machines are put to use, clinicians diagnose with their senses. They notice posture, muscle tone and bruises; they hear sadness in a tone of voice or the signs of impaired breathing; they feel for the pulse, for lumps; and they may smell metabolic disturbances' (2008, p. 39). This kind of initial sensory perception contradicts the model of Bayesian logic and procedures in which doctors are trained, even though doctors themselves recognise that clinical judgment involves 'subjective, context dependent reasoning' (Chitty, 2005), yet this is an essential part of practising. These embodied skills extend to the whereabouts of others, as shown when a nurse asks if the doctor has been yet. In doing this, she is 'tuning in' to the work and whereabouts of her colleague.

Gherardi outlines how craft trades require trained bodies - ones, that is, which have incorporated an expertise. It is through the body that 'an eye' (or 'an ear' or 'a nose') for something is acquired, so that aesthetic knowledge (Strati, 2003) also comprises the ability to develop a professional 'vision' in the broad sense' (Strati, 2003 in Gherardi, 2008, p. 251).

In the ED this proximal practice addresses a key aspect of how knowing is done through revisional sayings and doings involving reading notes, talk, and clinical examination as N5 does.

Simultaneously, proximal incorporates the spatio-temporal and emergent nature of working (Gherardi, 2006). This proximal practice is where nurses and doctors reconstitute their knowing dynamically as care happens, and is key to understanding how safe practice is enacted.

A proximal practice is so much a part of learning where action builds on an immediately preceding block of 'knowing' and/or 'understanding' (Vygotsky in Learning Theories Knowledgebase, 2012). 
The idea of a proximal practice also coheres with Vygotsky's view on the need to see practice as the judge of theory (Vygotsky, 1927 in Bradley, 2009, p. 79) and not the other way round. Theory had been preeminent (Bradley, 2009) over practice in considering the value of experience, whereas here the doing is positioned as paramount. A proximal practice accords with Vygotsky's notion of learning being a primarily sociocultural phenomenon in which humans act, share their experiences, and learn.

\section{Protocol-driven practices}

The second category of practice we examine is that of protocol-driven practices. These predominate in the ED, as both medicine and nursing are governed by protocols and are seen as central to safety. Doctors and nurses are taught particular ways of dealing with patients, particular illnesses and injuries. These include how they ought to follow a pathway for particular presentations, e.g. chest pain; how they should undertake guided history taking; suggested ways to interrogate the mental impairment of patients; clear questioning protocols around name-checking and a focus on the need to establish whether patients are in pain and so on.

The examples below illustrate how protocols of questioning, checking, revising and remaking of knowledge and knowing are enacted.

\section{$10 a m$}

N1 Okay. Are you allergic to any medicines? [the triage nurse repeats the question, as Jane Edna does not hear properly the first time]

\subsection{0am}

D1 Oh, okay. Alright. Do you have any allergies, Jane?

\section{At about 10.45 am}

N2 Jane, are you allergic to anything? [N2 was present when Jane Edna was first asked this question]

\section{At 1pm D1 asks again}

D1 No. Any significant allergic reaction?

$P \quad$ No, I'm not allergic to anything.

\section{At 11.48 am}

N4 Oh, we've got one here [talking about an allergy band]. So you're not allergic to anything? Shortly after midday, N4 comes to do the admission for Jane Edna. She checks Jane Edna's allergies once again: 


\section{Just after midday}

N4 Now, are you allergic to anything?

$P \quad$ No.

N4 And can you tell me your full name.

Within two minutes of the first question, experiencing what Roberts et al. term 'storage failure' (2003, p. 197), she asks Jane Edna again:

N4 You're not allergic to anything that you know of?

\section{At $4.20 \mathrm{pm}$}

RN And they will use some contrast. You're not allergic to any iodine or Betadine are you?

\section{A few seconds later}

RN You're not allergic to that at all?

Jane Edna is queried ten times about her allergies, twice by Nurse 4 in the space of two minutes: Oh, we've got one here. So you're not allergic to anything... Now, are you allergic to anything? Several minutes later: You're not allergic to anything that you know of? The RN (the radiography nurse) also checks twice. These are protocol driven questions and each nurse or doctor is responsible for their own knowledge about the patient and their ensuing actions. Even though N2 is present when Jane Edna is questioned by D1 she still asks the question herself; N4 asks the question three times and D1 also checks the same information twice.

Protocols are designed to reduce errors, provide quick solutions to common problems, and create general understandings between practitioners and thereby reduce critical incidents and eliminate harm as well as costly and lengthy investigations. The "correctness" of protocols are "based on the segmentation of therapy and intervention into an array of micro-actions ordered into a correct sequence, resulting from a rationalization of medical knowledge intended to deprive individual actors of margins of discretion [which] serves the purpose of limiting the margins of error caused by the human factor in rational medical reasons' (Bruni, Gherardi et al., 2007, p. 88).

Protocols assist to cut a swathe through the complexity of the materiality and knowing involved in each consultation as well as the complexity of each patient's presentation. Protocols around medication (and patient identification) facilitate a space for these to be checked and documented several times. Although care has a temporal linearity, it is usually co-constructed in a non-linear way by junior doctors, nurses and patients. As happens regularly, doctors and nurses arrive at a patient's bed, they begin their doings and sayings, they need to leave, they return. They ask the same things over and over again and do the same tests over and over again. Doings and sayings are connected to other doings and sayings, to the spatial features of ED care; to relationships between the nurses and 
the junior doctor who care for them; and to the specialised knowledges involved in treating them, expert evidence and tests. All these are integral to knowing in the ED.

Within the parameters of the ED's disciplinary and institutional exigencies, nurses and doctors must constitute and reconstitute their knowing several times during one patient's consultation, particularly if a patient has a long stay. Nurses and doctors' protocols are enacted in recursive professional engagement strategies enacted through doings and saying to manage knowing.

\section{Predictive/pre-emptive practices}

The third category of practices that we examine is how nurses and doctors predict and pre-empt knowing. As stated above, institutionally EDs are seen as places of expert knowledge - the predictive nature of differential diagnoses as well as the need to appear to know in this context involves preemptive and predictive sayings and doings. Handover protocols as well as differential diagnoses incorporate implicitly or explicitly significant forward thinking about what care or action in relation to patients might be required, or where a diagnosis might be leading. While handover protocols and differential diagnoses usually incorporate a history of patient care up to that minute, they are essentially focused on predicting or pre-empting future options for action. As such they are based on known and presumed medical and nursing knowledges, underpinning the practices themselves.

Below, a senior staff specialist sums up the process of forward thinking engaged in by nurses and doctors in the ED. He responds to the question: What happens to patients in the ED?

Alright so they [patients] get seen by a doctor. That doctor may or may not be senior enough to make a decision about what should happen next. Let's say it is a doctor such as myself that's senior enough to make decisions. So I'll see the patient, take a history, examine the patient, have some ideas in my head about what could be wrong, arrange some tests probably to test the hypotheses and evaluate the extent of their disease. In the meantime, start some initial treatment and then depending on the results of tests, once I've made a decision that we've gone as far as we can in the Emergency Department or gone as far as we should, then we'll make a decision about whether the patient needs to be admitted to hospital or needs to go home.

Kemmis' idea of craft knowledge - 'knowledge in the face of uncertainty (Kemmis, 2005, p. 396); the wisdom and experience that guides one in uncertain circumstances captures this notion of forward thinking well. To say this is to draw attention to practical reasoning as a feature of the conduct of a practice, which may accord with Schatzki's notion of 'practical understandings' (Schatzki, 2001; 2006). Nurses and doctors use craft knowledge to predict and pre-empt knowing about patients in the ED - much of which is reflected in their sayings qua doings. Tacit knowledge is not just made explicit (as Gherardi 2009, p. 354 warns) but it is made specific, and this is based on some fore knowledge of the practice, forward thinking of what might be required next. 
Using predictive or craft knowledge is one of the ways nurses and doctors manage their care of patients in the ED, i.e. even when their knowledge is not always certain. Not only do they bring to the bedside 'general and practical understandings' (Schatzki, 2001) of what to do, they must demonstrate early on, as they approach patients, a knowing of what to do and say.

\section{Prefigured participatory practices}

Finally we discuss how knowing-in-practice is accomplished through prefigured, situated engagement with patients, particularly participatory talk. We use the term 'prefigured' to underscore the recognisable, structured way that doctors learn about their patients' conditions and concerns through the medical interview. The term 'prefigured' reflects the predictable and established patterns of talk of the medical interview: taking a case history is structured and medical students are taught this structure.

As a practice, this talk is participatory. No matter how difficult the engagement might be, doctors and nurses must press on and try to understand and get information from their patients. The centrality of taking a history from, and engaging with patients dialogically has long been recognised as a central part of medical practice. Mishler's (1984) seminal work identified the sophisticated and purposeful function of the medical interview. The key role of participatory 'talk' in an institutional setting was also identified by Sarangi \& Roberts: 'Questioning and answering are [still] the prime organising elements of the goal orientated and constraining nature of [this] institutional [consultation]' (1999, p. 21). Thus in the institutional setting of the ED, talk is still one of the central ways that doctors, nurses and patients engage with each other. The action of talk, combined with evidence and physical symptoms, underscore how doctors and nurses resource their knowing. The persistence of engaging with patient overrides other practices that nurses and doctors have at their disposal to resource their knowing. For example even when they are aware that there are records in patient notes, or when other nurses or doctors report what they have done, they pursue the participatory activity.

D4 Now I talked to the doctors who saw you earlier

$P \quad$ Yeah

D4 But um this is really important for me and I know you've talked to a few doctors and you've given them your story too, like two or three people

$P \quad$ Yup

D4 But I need to know the story again too so I'm sorry, can you please tell me exactly what happened at 12 today...

In the extract below a senior doctor (D2) checks up on patient Wilson's medication. The conversation is difficult. It is cross-cultural. D2 is overseas trained and does not have English as his first language. The conversation also cuts across the expert/lay divide, even though Wilson, who has 
a chronic condition, is very knowledgeable about his illness and has more than lay knowledge.

Wilson becomes confused as the senior doctor insists on checking on the medication regimen himself. The senior doctor tends to repeat what he hears each time, possibly for his own clarification or confirmation. This further complicates the exchange. Despite the difficulties of the exchange, both parties must participate:

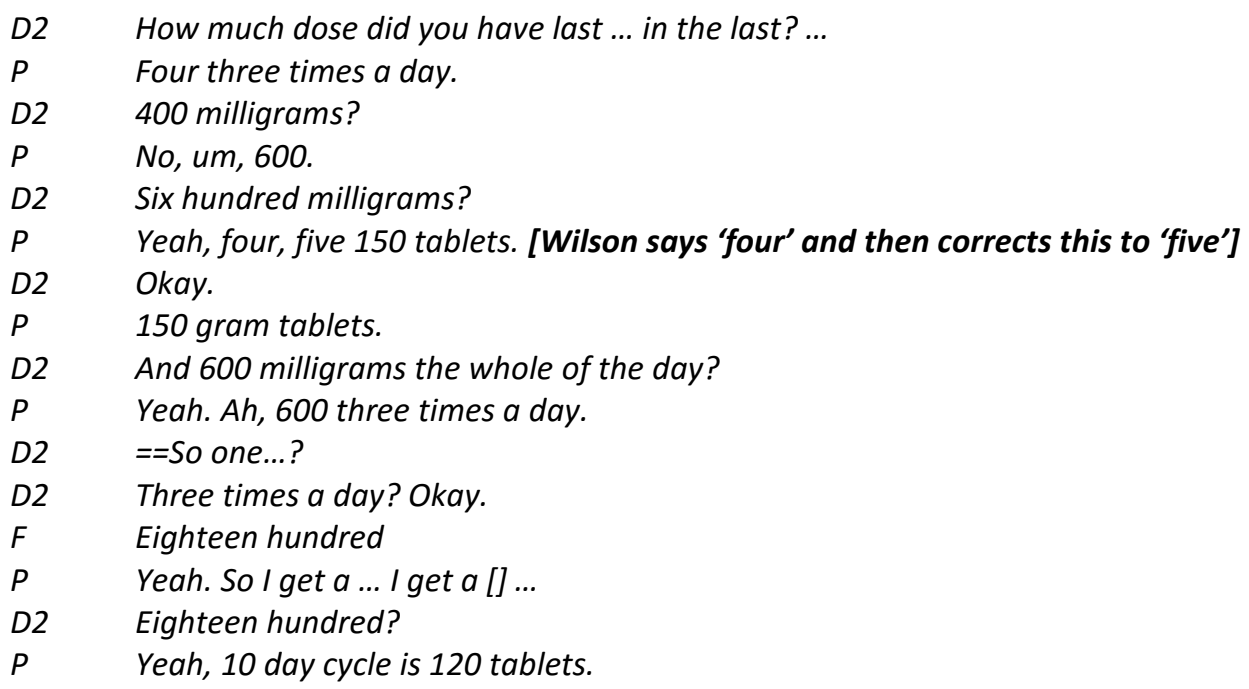

Wilson's wife has already handed in a list of his medications, and these have been recorded in the notes by one of the nurses. Both lists are in the file. However, the senior doctor seeks to participate once again with Wilson (through talk) to establish for himself what Wilson is taking. It takes 18 exchanges between the senior doctor (D2) and Wilson to re establish a twice-documented record of Wilson's medication history.

This persistence to participate and pursue knowing through talk is evident in a further example below. In this exchange, the complex negotiations between the junior doctor (D1) and the patient Joel's wife (F) are evident. Once again, the conversation is difficult. It is cross-cultural as D1 is overseas trained and does not have English as his first language; it is crossdisciplinary as Jill (F) is a nurse; and it also cuts across the expert/lay divide. Although Jill is there as a carer and not in an expert role, she does have extensive knowledge of Joel's illness, and expertise in caring for Joel. Jill has been caring for Joel, a palliative care patient, for four years. In that time, Jill has kept an extensive diarised history of his illness.

D1 Now, you have a, ah, diary. You were maintaining a diary? [D1 returns at 14.07 pm]

$F \quad$ Daily? Diary? [D1 \& $F$ fail to understand each other]

D1 Yeah?

$F \quad$ If you can understand my abbreviated words.

$P \quad==[]$ there.

D1 == Can you tell me when this, ah, left, ah renal cell carcinoma was diagnosed?

F Okay. [I love this]. Ah, mightn't have it that far back in this book.

N6 Oh hang on, it was, I've got it all in this page.

D1 Where you just five years back? 
F The bone scan was on the 5th May, [reading] "Bone scan today, very uncomfortable, coughing".

D1 Oh, 5th May of which year? [D1 seeks clarification]

F Fifth of May, they did the bone scan.

D1 Which year? [D1 again seeks clarification]

$F \quad$ This year. This year $==[]$.

D1 == No, no, no. I'm actually == asking right from the beginning because ...

$P \quad==[]$.

F Oh! Can't go - five years ago?

D1 Yes, == just so ...

$F \quad==$ Oh, I haven't got all that == information.

D1 == So it was five years back, left renal cell == carcinoma?

$F \quad==$ Yes. I thought you were talking about just - just the bones - bone here?

D1 No, I will come there == because I am ... [explains that he is seeking different information]

$F \quad==$ Oh, right back!

D1 ... I haven't == got any fax report from them. [D1 then explains why he wants to know]

F = = Oh, gosh no. Oh.

In Joel's consultation, this is the third time D1 enquires about when the first diagnosis was made, but the first time he writes the responses down. D1's history taking has been disrupted by the failure of Joel's previous notes to be faxed over in time - a socio-material resistance - notes D1 is relying on for a synopsis of Joel's history and a retake of which he now must do in real time. The failure of the notes to arrive is a dynamic and emergent event - an intervention that requires the junior doctor to adapt his work and responses in different ways. Because of Jill's and D1's divergent agendas (Jill wants an MRI and D1 wants to 'work up' a diagnosis), knowing about Joel throughout this consultation is a tortured event for Joel, Jill and the junior doctor.

This interaction illustrates the complexity of establishing the time of onset for Joel's condition, a prefigured framing. Despite the knowledge schema (Tannen \& Wallat, 1987) differences between Jill and D1, D1 persists in trying to understand the dimensions of Joel's illness through talk with Jill, even though N6 tells him she has the history documented already. For the junior doctor, this is not sufficient: D1 and N6 do not share their practice knowledges.

\section{The practices}

The four kinds of practices outlined above prevail in the ED. They are located in the past, present and future of ED work in that they bring together past knowledges and experiences into the immediacy of the ED context where new knowledges are occurring in the moment and look towards the future possibilities of further new knowledges. That is, these practices take account of what doctors and nurses bring to carrying out a practice from their prior formal learning; the procedural knowledge codified by institutions and disciplines as well as the enactments of knowledges that have been tried out or been in place many times before. As these unfold in time and space there are opportunities for change and learning. 
We now explore how attachments to practice knowledges impact on learning practices. We argue that the overriding paradigm of ED knowing/learning reflects nurses' and doctors' attachment to their disciplinary knowledges - the teleo-affective structuring (Schatzki, 2006) underpinning practices - to which nurses and doctors are attached (Reckwitz, 2002). As opportunities for learning/knowing emerge, attachments to practice knowledges intervene. As such, knowing is both emergent and teleological.

\section{The teleology of disciplinary knowing}

The teleo-affective structuring underpinning a practice (or practices) is key to understanding the learning/knowing paradigm of the ED. Schatzki identifies that an individual's and/or a group's motivations, beings, desires and beliefs, the 'timespace(s)' (Schatzki, 2009) in which he/she or they find themselves, is a constitutive dimension of their activity. This means that activity is always underpinned by attachment, and this attachment is teleological. If individuals and or groups have divergent timespaces, this can significantly impact on the relational climate between individuals or groups, such as nurses and doctors with different 'timespaces' in a particular setting.

For Schatzki, conflict and power manifest anywhere that either individuals or groups possess 'incompatible or disharmonious goals, projects, experiences, emotions, or desires' (Schatzki, 2009) and thus 'conflict and power are temporalspatial phenomena' (Schatzki, 2009). In the ED, differences in the knowledge hierarchies of doctors, nurses and patients, and their respective attachments to these disciplinary knowledges, as well as their different emotions, desires and projects, while overtly shared, are in disciplinary, if not individual, conflict. This, we contend, has a bearing on individual (and possibly collective) learning in the ED, as learning is mediated by selective 'legitimate' knowers and 'legitimised' information or knowledge: and these are enacted through sayings and doings.

As a learning space, in the ED, 'legitimate peripheral participation is at the heart of defining, or understanding, the nexus of relations through which situated learning occurs' (Macpherson, Antonacopoulou et al., 2010, p. 6), (see also Nugus, Greenfield et al., 2010). The pedagogic arrangements in the ED are disciplinarily based. There are no overt 'arrangements' that facilitate doctors learning from nurses, nor are there overt arrangements to facilitate nurses learning from doctors. This would seem reasonable given that nurses and doctors know different things and are, in a sense, interested in different things. Even though policy documents encourage interprofessional practice with the implicit intention that nurses and doctors will learn from, with and about each other (Garling, 2008), this learning will rarely be disciplinary. 
Information that is shared between nurses and doctors will be mostly about a patient's immediate health status (Reddy \& Spence, 2008; Paul \& Reddy, 2010): nurses and doctors do not share with each other, in a pedagogic sense, their practice knowledges. This is because practice knowledges are tied to nurses' and doctors' teleo-affective motivations, their desires, emotions and beliefs. Learning is thus largely confined to particular knowledges only and to particular relationships of learning (Creswick, Westbrook et al., 2009).

We now examine some examples of how this works in practice as nurses' and doctors' disciplinary knowledges are enacted through their doings and sayings. When nurses challenge what junior doctors do and know, it is medical knowledge that is enacted over nursing knowledge. We represent Jane Edna, introduced earlier, a short while into her consultation. N2 an experienced emergency nurse makes a suggestion to $\mathrm{D} 1$, a junior doctor:

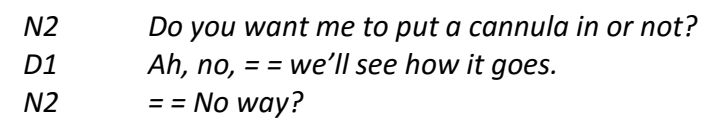

D1 (the junior doctor) rejects N2's suggestion to insert the cannula: medical authority is enacted. However, N2 checks D1's decision. Moments later, as Jane Edna is in pain again D1 decides to put in a cannula, and makes light of N2's pre-emptive suggestion which he had rejected earlier. He makes his own decision to insert the cannula, after requesting Jane Edna's blood pressure reading from N2. This decision may well be based on the blood pressure reading and could therefore be argued as premised on medical knowledge only. But N2 is an experienced ED nurse and may well have predicted the need for the cannula before D1 makes this decision himself. When N2 gives D1 the reading, he says:

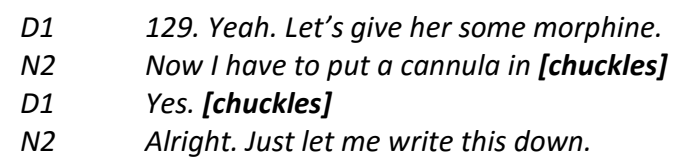

Arguably, N2 seeks to regain some control over her subsequent actions, stemming from what she might regard as her unrecognised expertise, by suggesting that she will follow D1's instruction after she has completed the writing task: Alright. Just let me write this down.

Disciplinary, institutional and material arrangements constrain or set up, particular possibilities for action; how individuals learn, how their doings and sayings draw on disciplinary knowledges. These are enacted through sayings and doings that reflect the hierarchical relationships between the junior doctor and the senior nurses, and in the actions they undertake.

For example, just prior to this exchange D1 has asked N2 earlier: How much anginine did we give her? This request is something N2 must respond to. N2 is 'obliged' to locate the paramedic notes and 'feed' D1 the information. D1 then asks N2 for the blood pressure reading as well. On both 
occasions, D1 is permitted to request information from N2: the medication information in the notes and so is the blood pressure reading. N2 has the information on the blood pressure to hand: the medication information she must locate in the paramedic notes. These are clinical details she is entitled to know. They are also details the junior doctor will source through her, not by himself - his disciplinary knowing involves other decisions such as when the cannula should be inserted, or in the example below, when to pronounce the final diagnosis (after further testing) even though other experienced nurses identify the problem.

In the exchange below between N2 and the junior doctor, D1, it is not clear whether N2 is professionally questioning what he (D1) is doing or whether she wants to learn more about why and when an ECG might be required. In the latter case, in an emergent way, there is an opportunity for her to learn medical practice knowledge. If D1 believes she is questioning him, he may feel threatened and might as a consequence be reluctant to inform her.

Either way the exchange illustrates the resistances, whatever their source, for cross-disciplinary learning to take place. D1 does not respond immediately to her question. N2 is then in a position where she herself must offer a possible reason for administering the second ECG and answer her own question. Finally, D1 offers a minimal response with no additional explanation.

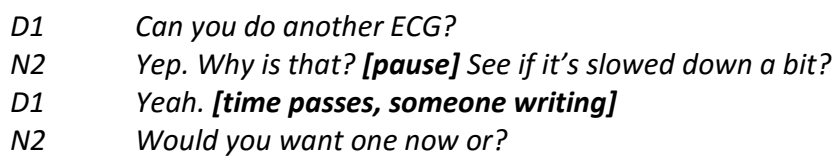

There is no audible response from D1to N2's final question on the audio recording: he must have responded non-verbally. Our notes document that he exits the room at this point. Soon after, N2 addresses Jane Edna. N2 is the person who explains to Jane Edna what is happening: N2 does the 'translation' work for Jane Edna even though she has had some difficulty in getting the medical explanation from D1 - who has left the room by this stage.

N2 Jane, I just have to do another heart tracing because you - it seems like, on the monitor your heart rate's come down a little bit. So we'll just see if there are any changes since the last one.

In another example below, one of the senior nurses (N6) suggests a possible diagnosis to D1. D1 arrives for his $10^{\text {th }}$ visit to Jane Edna's bedside. N6 suggests that the condition is epigastrium (reproduced in Manidis \& Scheeres, 2012, p. 113):

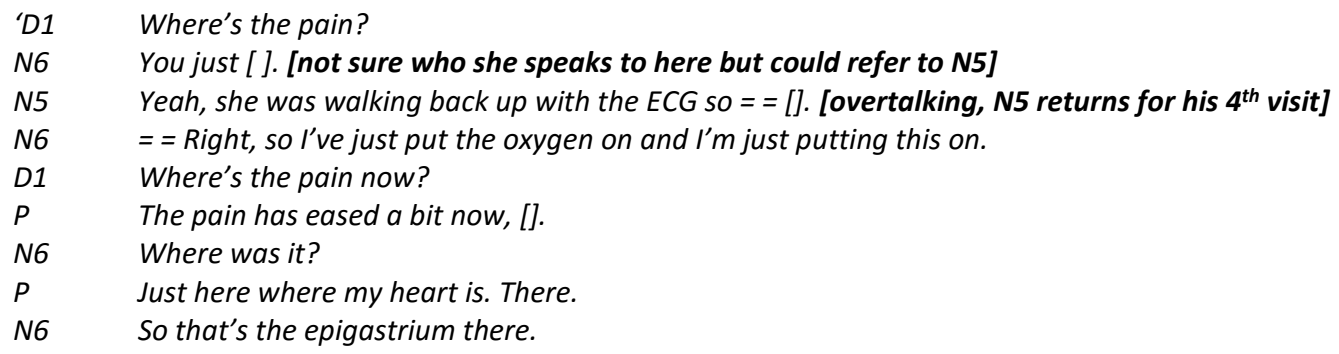


Yeah.

When N6 proposes that Jane Edna's pain is located in the (epigastrium), the junior doctor, (D1), acknowledges her contribution without committing himself: (Yeah) he says. He accedes to the suggestion of another ECG from N5 and on the basis of this evidence, tells Jane Edna: Okay, Jane. It's (the ECG reading) still the same. Okay. I think it's more of your stomach rather than your heart. Epigastrium is the ultimate diagnosis.

The paramedic who brought Jane Edna in informed D1 that she had a history of ischaemic heart disease. This aspect of Jane Edna's previous history is not documented in her triage notes, but may explain the doctor's investigative trajectory and his reluctance to commit to a preliminary diagnosis (proposed by N6) before he does the final ECG.

What the exchange illustrates once more is that practice knowledges are not shared between the junior doctor and the nurses. Furthermore, the exchange demonstrates how practice knowledges are enacted differently: D1 gathers further evidence before informing Jane Edna, tentatively, of her diagnosis. On the other hand, N6 states the condition outright in discussion with D1; a comment that D1 does not immediately endorse. In all the exchanges, the relationships of knowing/learning, whether they transpire between the patient and D1, or the nurses and the junior doctor, maintain conventional hierarchies of their disciplinary and lay/expert knowledges (Neal \& McKenzie, 2010). Opportunities for learning/knowing emerge in the moment, but teleological disciplinary paradigms (or lay/expert ones) are ever present and knowing is circumscribed.

\section{Discussion}

Knowledge is (re)produced in a particular way in the ED through the disciplinary-based learning/knowing paradigm. In this paradigm practices are 'bundled' (Schatzki, 2005) and they occur parallel to each through multiple disciplinary visits to patients' bedsides. Furthermore, our exchanges have shown that each nurse and doctor relies on and accepts selective 'legitimate' forms of evidence, defined by disciplinary and institutional exigencies and their own personal knowledges.

Our data shows that persistently, nurses and doctors engage in selective resourcing and selective displays of information with disciplinary-affiliated colleagues. As nurses (and patients) seek to participate in the treatment process, their doings and sayings, structured through different knowledges and attachments to these, are not always seen as legitimate in the participation process (Macpherson, Antonacopoulou et al., 2010).

Knowing is thus mediated epistemologically - and in the ED this happens to be disciplinary, which defines the relational dealings of nurses and doctors. From our data, doctors, nurses and patients 
accommodate or resist information that is communicated to them and this occurs largely along disciplinary, (or when patients are involved this occurs along lay/expert) lines. If information is consistent with their own disciplinary paradigms, or if it is packaged in a legitimised way (particularly when nurses seek to inform doctors, or when patients seek to inform nurses and doctors), then the more legitimate knower or 'other' (Vygotsky in Learning Theories Knowledgebase, 2012) will use this information to further resource their knowing.

If information is not packaged appropriately, or if information is not consistent with a disciplinary or lay/expert paradigm, i.e. with what a nurse or a patient it is entitled to know, the data show it can be either challenged or ignored. However, resistance is modulated if the evidence or legitimate information is something that the nurse is permitted to know (or in relevant history taking that the patient is permitted to know).

Legitimised information, and particularly how it is packaged, is key to understanding working/knowing in the ED. The recent introduction of iSoBar handover protocols (Australian Commission of Safety and Quality in Healthcare) reinforces the desirability of packaging information in specific ways, as paramedics, nurses and doctors are increasingly required to structure their handover spoken texts. On the one hand, there is merit in doing this as it saves time - and possibly therefore a life -, but the structuring privileges particular kinds of evidence such as bio-medical knowledge. A fixed structure on the other hand might constrain opportunities for providing information that may be relevant to the patient's condition but it might not be legitimised within this structure.

New information and knowledge about patients and colleagues emerges continually, as care happens. Knowing has the potential to be dynamic, yet our data illustrate that although information is exchanged between nurses and doctors or between nurses, doctors and patients, as seen in the examples above, this does not necessarily translate into knowing. Even though emergent information may be offered or be forthcoming, in their practice roles, doctors and nurses resist emergent information (if it is not legitimate) and they resist participation from, mostly, crossdisciplinary colleagues. In this way, each 'group' maintains its disciplinary integrity and authority. Disciplinary doings, beings and sayings prescribe knowing/learning in the ED setting. Knowing is anchored therefore not just in the moment, but also in the relational (disciplinary) paradigm of doctors' and nurses' practices. Thus, knowing, although portrayed as emergent, is also connected to the epistemic legitimacy of doctors, nurses and patients, which is teleological, teleo-affective and extra-situational, i.e. it is not only situated in the here and now but also anchored in a past and a future of hierarchical expertise. 
Contu \& Wilmott agree that 'actions that comprise learning are thus conceived to be embedded in their historical conditions of possibility, and language is understood to be the principal medium of communication for the (re)production of social practices' (Contu \& Willmott, 2003, p. 287). In their words " "information sharing" within "communities" [is] historically contingent' (Contu \& Willmott, 2003 , p. 294). Thus, through sayings, medical knowledge dominates when contested by nurses, and medical and nursing knowledge dominate when contested by patients. This holds unless the emergent information is in a particular evidential form that is legitimised, i.e. temperatures, $\mathrm{X}$-rays, allergies, illness narrative etc. The potential for learning across disciplinary and across lay/expert boundaries is restricted by each of the participants in turn - based on their legitimacy as knowers, and or the legitimacy of their knowledge contribution. This is no more evident than when doctors circumscribe what they wish to hear from patients as they persistently pursue template history taking protocols.

\section{Conclusions}

Our findings confirm that knowing is 'constituted and reconstituted every day in practice' (Orlikowski, 2002, p. 269). This is done both individually and collectively and in a dynamic way in the $E D$, driven as it is by peak periods of presentation, the temporal patterns of work, nursing and medical shifts, tea and lunch breaks, the length of ED stays, the complex presentations of patients and protocols of care, and patients' presentations.

The article has explored the idea that although knowing is generally portrayed as emergent (Gherardi, 2006; 2008; Nicolini, 2011), in the ED - and possibly in other organisational settings -, knowing is also connected to the taxonomic (and historical) hierarchy of doctors', nurses' and patients' knowledges and is thus also teleological. Knowing is not just situated in the here and now (i.e. emergent) but it is also anchored in a past, a present and a future of disciplinary expertise. This finding has implications for the way we think about workplace learning, and workplace change, particularly in sites that have well-documented (and contested) professional narratives.

If learning is emergent and teleological, we must take account of the teleo-affective dimensions of knowing in a workplace setting. These dimensions are located not merely in the here and now of practice, but in the past, present and future of practice. Although clinical redesign is a top priority of healthcare services in Australia and abroad (NSW Department of Health, 2005; South Eastern Sydney and Illawarra Health Service, 2006; National Health and Hospitals Reform Commission, 2009), organisational changes are likely to be slow and incremental. The open-endedness and capacity of a practice to be differently executed the next time it is done (Schatzki, 2011), provides some hope for 
change; there is always the potential for practices to be different. However, even though change and stability are inherent in practices and practising, practice 'understandings and repertoires tend toward inertia; indeed, their inertia is crucial to the pervasive persistence of bundles, a conservatism inherent to social life. This conservatism is all the more extensive given that the same practical understandings and bodily repertoires can underlie multiple bundles' (Schatzki, 2011, p. 20). In the $E D$, change occurs in the pace and institutional configuration of activity; not in the essence of disciplinary activity.

Practice knowledges that nurses and doctors bring to the ED reflect extant hierarchies of disciplinary knowing. These metaphorical 'timespaces' (Schatzki, 2009) realign in the actual 'time' and 'space' of the ED - amidst the ED's unique work, knowledges, space, language, artefacts and people, its site ontology (Schatzki, 2005). Institutionally, nurses and doctors draw on disciplinary teleologies (old learnings) and extend these into institutional repertoires of practice (new learnings). Knowing in practice is the centerpiece of emergent and teleological activities. As Hager and Johnsson have argued elsewhere (2012), knowledge is not just an object captured by means of mental schemes; rather it is implicated in a practical and collective activity that illuminates what it means to practise knowing.

\section{References}

Australian Commission of Safety and Quality in Healthcare. "iSoBAR for Inter-Hospital Patient Transfers." Retrieved 3 November 2011, from <http://www.safetyandquality.gov.au/internet/safety/publishing.nsf/content/PriorityProgra m-05_IHPT>

Bourhis, R., Roth, S. \& Macqueen, G. (1989). 'Communication In The Hospital Setting - A Survey Of Medical And Everyday Language Use Amongst Patients, Nurses And Doctors', Social Science \& Medicine, vol. 28, no. 4, pp. 339-46.

Bradley, B. S. (2009). Rethinking 'Experience" in Professional Practice: Lessons from Clinical Psychology, in: B. Green (ed.), Understanding and Researching Professional Practice (Amsterdam, Sense Publishers).

Bruni, A., S. Gherardi, et al. (2007). "Knowing in a system of fragmented knowledge." Mind, Culture, and Activity 14(1 \& 2): 83.

Chitty, R. N. (2005). "Is there a Bayesian doctor in the house?" British Medical Journal 330(June): 1390.

Contu, A. and H. Willmott (2003). "Re-embedding Situatedness: The Importance of Power Relations in Learning Theory." Organization Science 14(2): 283.

Creswick, N., J. I. Westbrook, et al. (2009). "Understanding communication networks in the emergency department." BMC Health Services Research 9(247): 1.

Eisenberg, E. M., A. G. Murphy, et al. (2005). "Communication in Emergency Medicine: Implications for Patient Safety." Communication Monographs 72(4): 390. 
Fischer, M. and G. Ereaut (2012). When doctors and patients talk: making sense of the consultation (London, The Health Foundation).

Garling, P. (2008). Final Report of the Special Commission of Inquiry: Acute Care in NSW Public Hospitals, 2008 - Overview. (NSW Department of Health, NSW Department of Health).

Gherardi, S. (2006). Organizational Knowledge: The Texture of Workplace Learning (London, Blackwell).

Gherardi, S. (2008). Situated Knowledge and Situated Action: What do Practice-Based Studies Promise? in: D. Barry \&. H. Hansen (eds.), The SAGE Handbook of New Approaches in Management and Organization (Los Angeles, Sage).

Gherardi, S. (2009). "Knowing and learning in practice-based studies: an introduction." Learning Organization 16(5): 352.

Hager, P. (2011). Theories of Workplace Learning, in: M. Malloch, L. Cairns, K. Evans and B. N. O'Connor (eds.), The Sage Handbook of Workplace Learning (London, Sage).

Hager, P. and M. Johnsson (2012), in: P. Hager, A. Lee and A. Reich (eds.), Collective learning practice. Practice, Learning and Change: Practice-Theory Perspectives on Professional Learning (Dordrecht, Springer).

Hor, S. (2011). Accountabilities and Patient Safety: A study of mess and multiplicities. Doctor of Philosophy, University of Technology Sydney.

Kemmis, S. (2005). "Knowing Practice:searching for saliences." Pedagogy, Culture and Society 13(3): 391.

Learning Theories Knowledgebase. (2012). "Social Development Theory (Vygotsky)." Retrieved 20 April 2012, from <http://www.learning-theories.com/vygotskys-social-learning-theory.html>

Macpherson, A., E. Antonacopoulou, et al. (2010). Practicing Communities of Practice: Translating Strategy into situated learning. Organization Learning Knowledge Capabilities Conference, Boston, U.S.A.

Manidis, M. and H. Scheeres (2012). Towards understanding workplace learning through theorising practice: at work in hospital emergency departments, in: P. Hager, A. Lee and A. Reich. (eds.), Practice, Learning and Change: practice-theory perspectives on professional learning (Dordrecht, Springer).

Mishler, E. G. (1984). The Discourse of Medicine: Dialectics of Medical Interviews. (New Jersey, Ablex Publishing Corporation).

Mol, A. (2008). The Logic of Care. Health and the problem of patient choice (London, Routledge).

National Health and Hospitals Reform Commission (2009). A Healthier Future For All Australians Final Report of the National Health and Hospitals Reform Commission - June 2009. (National Health and Hospitals Reform, Commonwealth of Australia).

Neal, D. M. and P. J. McKenzie (2010). Putting the pieces together: Endometriosis blogs, cognitive authority, and collaborative information behaviour, Faculty of Information and Media Studies, UWO, London, Ontario.

Nicolini, D. (2011). "Practice as the Site of Knowing: Insights from the Field of Telemedicine." Organization Science 22(3): 602.

NSW Department of Health (2005). Clinical Services Redesign Program: Redesigning a better patient journey (Sydney, NSW Department of Health). 
Nugus, P., D. Greenfield, et al. (2010). "How and where clinicians exercise power: Interprofessional relations in health care." Social Science and Medicine 71: 898.

Orlikowski, W. J. (2002). "Knowing in practice: Enacting a collective capability in distributed organizing." Organization Science 13(3): 249.

Paul, S. A. and M. C. Reddy (2010). Understanding Together: Sensemaking in Collaborative Information Seeking. ACM Conference on Computer Supported Cooperative Work (CSCW 2012). Savannah, Georgia USA.

Rampton, B. (2007). "Neo-hymesian linguistic ethnography in the United Kingdom." Journal of Sociolinguistics 11(5): 584.

Reckwitz, A. (2002). "Toward a Theory of Social Practices: A Development in Culturalist Theorizing." European Journal of Social Theory 5(2): 243.

Reddy, M. C. and P. R. Spence (2008). "Collaborative information seeking: A field study of a multidisciplinary patient care team." Information Processing \& Management 44(1): 242.

Roberts, C., V. Wass, et al. (2003). "A discourse analysis study of 'good' and 'poor' communication in an OSCE: a proposed new framework for teaching students." Medical Education 37: 192.

Roter, D. (2000). "The enduring and evolving nature of the patient-physician relationship." Patient Education and Counselling 39: 5.

Sarangi, S. and C. Roberts (1999). The dynamics of interactional and institutional orders, in: S. Sarangi and C. Roberts (eds.), Talk, Work and Institutional Oder: Discourse in Medical, Mediation and Management Settings (New York, Mouton de Gruyter).

Schatzki, T. R. (2001). Introduction: Practice Theory, in: T. R. Schatzki, K. Knorr Cetina and E. von Savigny (eds.), The Practice Turn in Contemporary Theory (London, Routledge).

Schatzki, T. R. (2001). Practice mind-ed orders. The Practice Turn in Contemporary Theory, in: T. R. Schatzki, K. Knorr Cetina and E. von Savigny (eds.) (Oxon, Routledge).

Schatzki, T. R. (2002). The site of the social: a philosophical account of the constitution of social life and change (Pennsylvania, Pennsylvanie State University Press).

Schatzki, T. R. (2005). "The sites of organizations." Organization Studies 26(3): 465.

Schatzki, T. R. (2006). "On organizations as they happen." Organization Studies 27(12): 1863.

Schatzki, T. R. (2009). Timespace and the Organization of Social Life, in E. Shove, F. Trentmann and R. Wilk, (eds.), Time, Consumption and Everyday Life: Practice, Matieriality and Culture (Oxford, Berg).

Schatzki, T. R. (2011). Lecture on practices: incorporating paper "The Edge of Change". Presentation to Centre for Research in Learning and Change. University of Technology, Sydney.

Schatzki, T. R. (2012). A Primer on Practices: Theory and Research, in: J. Higgs et al. (eds.), PracticeBased Education: Perspectives and Strategies (Sense Publishers).

South Eastern Sydney and Illawarra Health Service. (2006). "Clinical Services Redesign Program." Retrieved 9 September 2011, from <http://www.health.nsw.gov.au/resources/quality/knowledgemgt/pdf/km_sesiahs.pdf>

Strati, A. (2003). Knowing in practice:aesthetic understanding and tacit knowledge, in: D. Nicolini, S. Gherardi and D. Yanow (eds.), Knowing in Organizations (Armonk, M. E. Sharpe).

Strati, A. (2007). "Sensible knowledge and practice-based learning." Management Learning 38(1): 61. 
Tannen, D. and C. Wallat (1987). "Interactive Frames and Knowledge Schemas in Interaction: Examples from a Medical Examination/Interview." Social Psychology Quarterly 50(2): 205.

Yamauchi, Y. (2006). Knowing and not knowing in work practice: three ethnographic studies. PhD, University of California, Los Angeles.

Yanow, D. (2000). "Seeing organizational learning: A "cultural" view." Organization 7(2): 247.

i Australian Research Council (ARC) Linkage project LP0775435, Emergency Communication: Addressing the challenges in healthcare discourses and practices.

ii Hospitals linked to universities and therefore to training doctors, nurses and other allied health workers

iii Except for telemedicine (Nicolini 2011) where doctors, nurses and patients are not necessarily geographically co located 